DOI: https://doi.org/10.24867/07BE20Vidric

\title{
ANALIZA RADA RELEJNE ZAŠTITE U SEVERNOAMERIČKIM DISTRIBUTIVNIM MREŽAMA
}

\section{ANALYSIS OF RELAY PROTECTION OPERATION IN NORTH AMERICAN DISTRIBUTION NETWORKS}

Dragana Vidrić, Fakultet tehničkih nauka, Novi Sad

\section{Oblast - ELEKTROTEHNIKA I RAČUNARSTVO}

Kratak sadržaj - U ovom radu opisane su osnovne karakteristike severno američkih distributivnih mreža $i$ nove tendencije razvoja i upetljavanja u svrhu sigurnosti. Navedeni su opšti zahtevi koji se postavljaju pred relejnu zaštitu $i$ date su osnovne informacije o prekostrujnim $i$ distanitnim relejima. Predstavljene su funkcije relejne zaštite. Na primeru jednopolne šeme severnoameričke distributivne mreže, prikazano je rešenje pri promeni uklopnog stanja mreže.
\end{abstract}

Ključne reči: srednjenaponske nebalansirane distributivne mreže, principi rada relejne zaštite, adaptivna relejna zaštita, analiza osetljivosti relejne zaštite

\begin{abstract}
This paper describes the basic characteristics of North American distribution networks and the new tendencies of development and interference for safety purposes. General requirements for relay protection and basic information on overcurrent and distance relays are given. The relay protection functions are presented. In the example of a single-pole North American distribution network, a solution is shown when changing the switching state of the network.
\end{abstract}

Keywords: distribution unbalanced networks, functionality od relay protection, adaptive relay protection, relay protection sensitivity analysis

\section{UVOD}

Osnovni cilj primene relejne zaštite je najbrže moguće isključenje elementa, odnosno dela elektroenergetskog sistema prilikom nekog abnormalnog stanja, inicijalizacijom odgovarajućih upravljačkih akcija, uz očuvanje funkcionalnosti i održanje stabilnosti ostalog dela sistema.

Releji moraju izolovati samo deo mreže pod kvarom, omogućavajući nastavak rada nad delom mreže bez kvara.

Time se omogućava nesmetan rad mreže u kojoj su instalisani releji. Srednjenaponske distributivne mreže odlikuju se radijalnim ili slaboupetljanim pogonom, gde se različite vrste relejnih zaštita primenjuju [2].

U glavi 2 dat je opis osnovnih karakteristika distributivnih mreža i nove tendencije razvoja i upetljavanja u svrhu sigurnosti.

\footnotetext{
NAPOMENA:

Ovaj rad proistekao je iz master rada čiji mentor je dr Duško Bekut, redovni profesor.
}

Takođe, dat je uporedni prikaz dva osnovna tipa mreža u svetu: evropskih i severnoameričkih. U glavi 3 i 4 se opisuju najčešće vrste relejne zaštite koje se koriste u radijalnim i slaboupetljanim distributivnim mrežama prekostrujna i distantna, kao i detaljan opis konkretnih tipova i funkcionalnost releja koji se koriste u severnoameričkom distributivnom području. U petoj i šetoj glavi je izložen praktičan deo rad, data je jednopolna šema distributivne transformatorske stanice, kao i predložena softverska rešenja koje daje funkcija Adaptivna relejna zaštita, pri promeni usklopnog stanja mreže. U sedmoj i osmoj glavi je naveden zaključak rada i korišćena literatura, respektivno.

\section{OSNOVE DISTRIBUTIVNIH MREŽA}

Elektrifikacija koja je započela početkom 20-tog veka suštinski je doprinela produktivnosti i industrijalizaciji sveta [2]. U početku nije bilo mnogo potrošača, ali je njihov broj ipak bio preveliki da bi se distributivne mreže mogle upetljavati i da bi se tako upetljavanje u svrhu sigurnosti finansijski isplatilo. Vremenom se broj potrošača povećava i sama struktura potrošača se menja postoji sve više uređaja u običnim domaćinstvima, motori $\mathrm{u}$ industrijskim zonama imaju sve veće snage. To je dovelo do usložnjavanja distributivnih mreža i konačnog opredjeljenja za radijalnost kao osnovu funkcionalnosti ovakvih mreža [3]. Ipak, neka potrošačka područja su zahtevala veći stepen sigurnosti i pouzdanosti pa se tamo pristupilo maloj modifikaciji mreža - uveden je koncept slabo upetljanosti u takvim područjima

\subsection{Upetljane distributivne mreže}

Kao što je spomenuto, jedan od najefikasnijih načina za rešavanje problema ispada potrošača je upetljavanje mreža. Područja koja su od velikog ekonomskog ili društvenog značaja kao što su bolnice, aerodromi, vojni objekti ili jednostavno gusta potrošačka područja zahtevaju konstantno napajanje, da ne bi došlo do većih socijalnih, društvenih ili ekonomskih posledica. U svetu ne postoje jedinstvena rešenja za navedene probleme, pa tako i ne postoji obrazac konfiguracije distributivnih mreža. Generalno, kao posebni tipovi distributivnih mreža izdvojili su se evropski i severnoamerički tip [4].

Elektroenergetski sistemi u Evropi se u praksi razlikuju u zavisnosti od država i zakonskih propisa. Opšte smernice prilikom konfiguracije sistema su da se prenosne mreže upetljavaju radi zadovoljenja sigurnosti tipa ,n-1“, dok se distributivne mreže izvode kao radijalne, ukoliko struktura potrošačkog područja ne zahteva suprotno. 
Ukoliko postoji potreba za upetljavanjem, obično se u evropskim mrežama izvodi neuporedivo manji broj petlji. Zbog toga postoji i razlika u terminologiji pa se ovakve mreže nazivaju slaboupetljane distributivne mreže (eng. Weakly Meshed Network) [4].

Struktura čitavog elektroenergetskog sistema Severnoj Americi se razlikuje u odnosu na evropske mreže, ali te razlike posebno dolaze do izražaja u distributivnim mrežama. Distributivne stanice se obično izvode kao sistem dva transformatora u bloku. Ovi transformatori su dimenzionisani da mogu da preuzmu opterećenje druge stanice ukoliko dođe do njenog ispada. Ove stanice obično sa napona $230 \mathrm{kV}$ ili $35 \mathrm{kV}$ prebacuju na napon mrežnog transformatora, koji je u opsegu $4 \mathrm{kV}-35 \mathrm{kV}$. Mrežni transformatori spuštaju napon na potrošački, priključni napon $(120 \mathrm{~V}$ ili $240 \mathrm{~V})$. Na slici 2.1 dat je jedan primer ove konfiguracije. Izvod prikazan na slici je samo jedan od mnoštva koji se napaja sa date stanice. On je izveden kao nadzemni vod ili podzemni kabl velike prenosne moći, u zavisnosti od stepena urbanizma potrošačkog područja. Sa glavne grane izvoda granaju se laterali koji mogu biti različitih faznosti i opterećenja i zaštićeni su topljivim osiguračima ili prekidačima. Ovakvi laterali su srednjenaponski i na njima se nalazi nekoliko mrežnih transformatora. Ovi transformatori se razlikuju od evropskih jer su uglavnom monofazni; u slučaju da su trofazni izvode se kao tri odvojena monofazna transformatora.

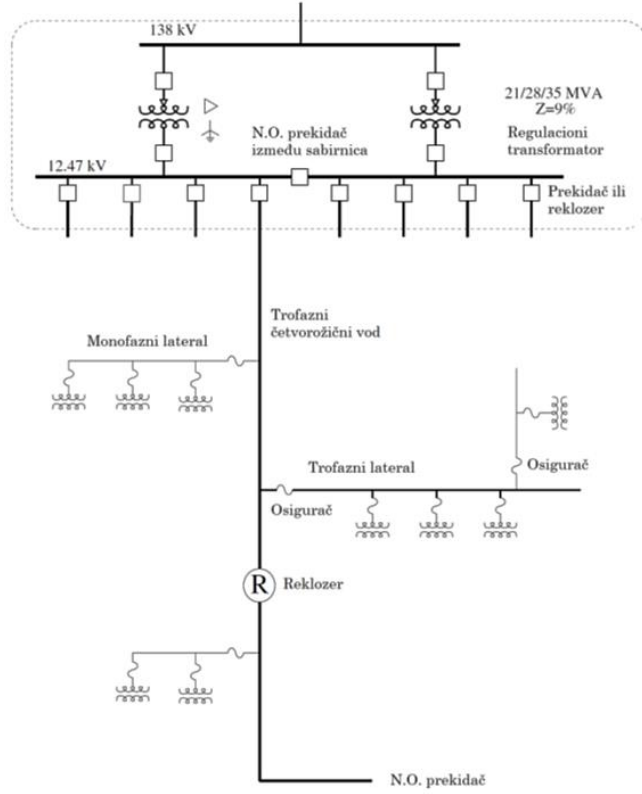

Slika 2.1 - Primer distributivne stanice/mreže severnoameričkog tipa

\section{ZAŠTITA U RADIJALNIM DISTRIBUTIVNIM MREŽAMA}

Krajem devetnaestog i početkom dvadesetog veka za zaštitu elektroenergetskog sistema počinju da se koriste releji, gde se pod pojmom relej podrazumeva uređaj koji je napravljen tako da, kada se na njegove ulaze dovodi električna, mehanička ili neka druga veličina odgovarajućeg intenziteta, deluje na neki unapred određen način. Pri tome, osigurači i slični uređaji ne spadaju u releje, jer je njihova funkcionalnost nepovratno izgubljena nakon jednog delovanja [2]. Relej je uređaj koji služi za detekciju abnormalnih pogonskih stanja elemenata i delova sistema, i na osnovu toga vrši inicijalizaciju odgovarajućih upravljačkih akcija za obezbeđenje normalnog pogona. Pri ispunjenju ovog cilja potrebno je ispuniti nekoliko opštih zahteva: selektivnost, brzina reagovanja, osetljivost, pouzdanost, cena itd.

Relejna zaštita može biti klasifikovana u skladu sa načinom na koji obavlja svoju funkciju. Postoje: prekostrujni, distantni, diferencijalni, podnaponski, drugi releji. U nastavku rada je analizirana prekostrujna i distantna zaštita.

\subsection{Prekostrujna zaštita}

Prekostrujna zaštita generalno predstavlja najčešći oblik zaštite koja se koristi za eliminisanje kvarova u mreži, detektovanjem velikih vrednosti struje kvara. Prekostrujni releji su najrasprostranjenija vrsta zaštite zbog relativno niske cene i širokog opsega struje kvara koje mogu detektovati. Na osnovu radne karakteristike releja, postoji podela na tri glavne grupe: trenutni prekostrujni releji, releji sa strujno nezavisnom karakteristikom i releji sa strujno zavisnom karakteristikom.

\subsection{Distantna zaštita}

Rad distantnih releja nije regulisan striktno strujom ili snagom, već zavisi od odnosa primenjenog napona i struje. Releji stoga efektivno mere impedansu u zoni koju štite. U uslovima kvara, napon je degradiran, i tada se struja u velikom intenzitetu povećava. Ovo se detektuje distantnim relejom kada impedansa opadne tokom kvara. Iniciran je prekid napajanja, koji se obavlja slanjem signala strujnom prekidaču da prekine strujno kolo. Ovaj tip releja (eng. distance relays) koristi se u nadzemnim i kablovskim mrežama. Prednost im se ogleda u brzini, kada druge zaštite nisu u mogućnosti da ispoštuju zahtevane vremenske uslove. Impedansom može da se odredi dužina nadzemnog voda ili kabla, te se distantna zaštita naziva i zaštita distantom impedansom (eng. Distance impedance).

Kada se posmatra karakteristika distantnog releja, razlikuju se tri tipa: impedantna, ugaono-admitantna i kvadrilateralna.

\section{REALIZACIJA RELEJNE ZAŠTITE U SEVERNOAMERIČKIM DISTRIBUTIVNIM MREŽAMA}

$\mathrm{U}$ ovom radu, realizacija relejne zaštite se ogleda $u$ korišćenju dve funkcije - Adaptivna relejna zaštita (u daljem tekstu ARZ) i Analiza osetljivosti relejne zaštite (u daljem tekstu AORZ), koje su deo slobodno dostupne trajal verzije softvera za proračune kratkih spojeva i osetljivosti zaštite. ARZ se koristi za trenutni odabir najbolje grupe (podešenja) zaštite u okviru zaštitne opreme (engl. Protection equipment), dok se AORZ koristi za planiranje. Zaštitna oprema se nalazi na reklozerima i prekidačima koji se nalaze na samom početku izvoda (engl. feeder head breaker), s tim da se tipovi releja koji se na njima nalaze razlikuju. Prekidači (na samom početku izvoda) mogu da imaju oba tipa zaštite (i prekostrujnu i distantnu), dok reklozeri koji se nalaze u dublje u mreži imaju samo prekostrujne releje na sebi. Svaka zaštitna oprema može imati jednu ili više grupa sa različitim podešenjima. U nastavku rada biće izloženi primeri tri najčešće korišćena releja u severnoameričkim distributivnim mrežama, kao i opisana njhova funkcionalnost rada. 


\section{1,51“ - vremenski fazni prekostrujni relej}

Štiti objekte od tropolnih kratkih spojeva, s tim da pokriva čitavu primarnu i sekundarnu zonu, preciznije seže do normalno otvorenog prekidača, distributivne stanice, osigurača i drugog po redu reklozera - slika 4.1.

Algoritam pomenutih funkcija (ARZ i AORZ) se bazira na tome da se na tim mestima simulira tropolni kratak spoj i od svih vrednosti struja bira se najmanja, koja se dalje upoređuje sa podešenjem releja.

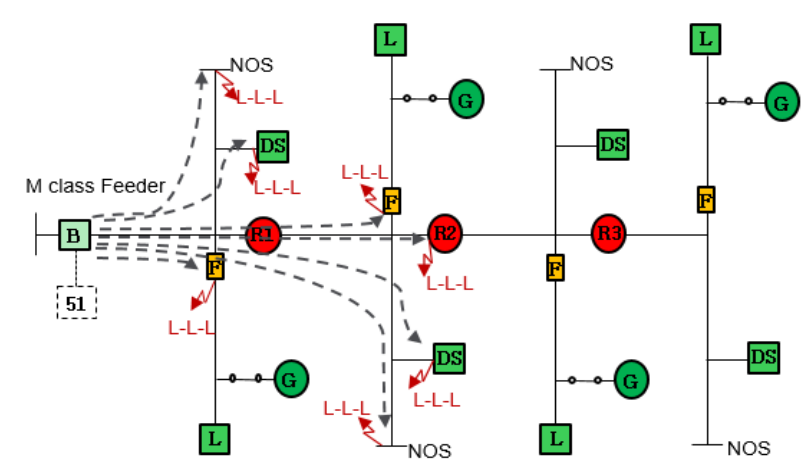

Slika 4.1 - Princip rada 51 releja

Na slici su korišćene sledeće oznake:

$\mathrm{B}$ - prekidač na početku izvoda,

R1, R2, R3 - reklozeri,

$\mathrm{L}$ - potrošač,

NOS - normalno otvoren prekidač,

DS - distributivna stanica

L-L-L - tropolni kratak spoj,

L-G - zemljospoj,

$\mathrm{G}$ - distributivni generator ili sinhrona mašina,

$\mathrm{F}$ - osigurač.

\section{2, ,51N FAST RECLOSER“ zaštita}

Za razliku od prethodnog releja, ova zaštita se postavlja na reklozerima, otuda i ime. Štiti objekte od jednopolnih kratkih spojeva, a pritom pokriva $100 \%$ primarne zone, tj seže do normalno otvorenog prekidača, distributivne stanice, prvog susednog reklozera i osigurača (slika 4.2).

Algoritam funkcija se bazira na tome da se na tim mestima simuliraju jednopolni kratki spojevi i bira se najmanja vrednost struje kratkog spoja, koja se upoređuje sa podešenjem releja. Vreme delovanja je $0.1 \mathrm{~s}$.

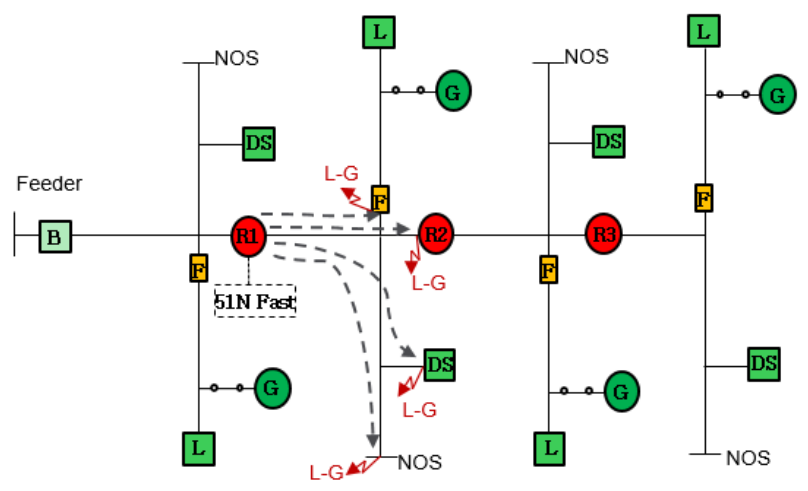

Slika 4.2 - Princip rada „,51N FAST Recloser“ zaštite

\section{$4.3,21 G 2 “$ - zemljospojni distantni relej (zona štićenja 2)}

Štiti objekte od jednopolnih kratkih spojeva. Pokriva $100 \%$ primarne zone, tj seže do normalno otvorenog prekidača, distributivne stanice, reklozera i prvog osigurača (Slika 4.3). Na tim mestima se simuliraju jednopolni kratki spojevi i bira se najmanja vrednost struje kratkog spoja, koja se upoređuje sa podešenjem releja. Ima kvadrilateralnu karakteristiku.

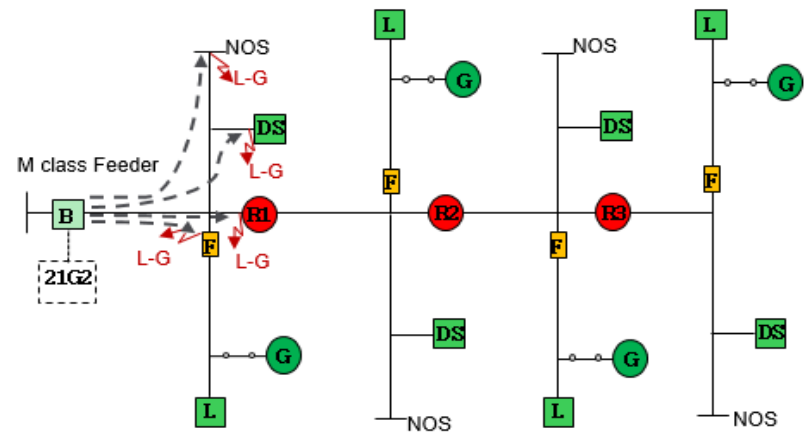

Slika 4.3 - Princip rada $21 G 2$ releja

\section{ADAPTIVNA RELEJNA ZAŠTITA}

Adaptivna relejna zaštita predstavlja izuzetno važan koncept koji je nastao kao rezultat uvođenja mikroprocesorskih zaštita, inteligentnih elektronskih uređaja i naprednih komunikacionih sistema. U samoj sustini adaptivne zaštite, nalazi se centralizovani algoritam, koji funkcioniše na bazi poređenja aktuelnih podešenja zaštite i trenutnog stanja zaštita u mreži. Na ovaj način, detektuju se zaštitni uređaji sa neadekvatnim podešenjima i fokus se stavlja na traženje optimalne zaštite, ukoliko je trenutna zaštita mreže neadekvatna. Adaptivna relejna zaštita, kao deo slobodno dostupne trajal verzije softvera za proračune kratkih spojeva i osetljivosti zaštite, najčešće se pokreće za izvode ili celu transformatorsku stanicu. Nakon uspešnog izvršenja funkcije, dostupan je izveštaj o svim neophodnih informacijama.

\subsection{Praktična realizacija Adaptivne relejne zaštite}

Distributivna transformatorska stanica se nalazi na području Severne Amerike. Na jednopolnoj šemi prikazanoj na slici 5.1 mogu se primetiti dva tronamotajna transformatora koja rade u paraleli. Sistemi glavnih sabirnica na kojima se nalaze odgovarajući izvodi sa prekidačkom opremom, relejnom zaštitom i trenutnom aktivnom grupom (podešenjem) releja.

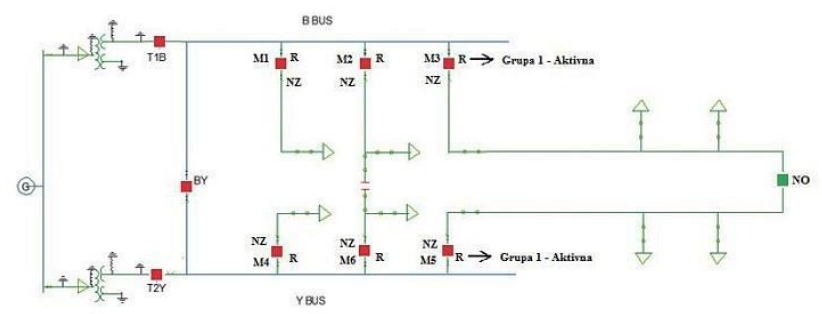

Slika 5.1 - Jednopolna šema distributivne transformatorske stanice $u$ inicijalnom stanju

Gde su:

$\mathrm{NZ}$ - normalno zatvoreni prekidač,

$\mathrm{NO}$ - normalno otvoreni prekidač,

M1, M2... - imena izvoda. 
Izveštaj ARZ-a za zaštitnu opremu na M3 izvodu izgleda kao u tabeli 5.1.

Tabela 5.1. Izveštaj ARZ-a pri inicijalnom stanju mreže sa slike 5.1

\begin{tabular}{|c|c|c|c|c|c|c|c|c|}
\hline \multirow[b]{2}{*}{$\begin{array}{c}\text { Tip } \\
\text { releja }\end{array}$} & \multirow[b]{2}{*}{ Zona } & \multicolumn{3}{|c|}{ Osetljivost } & \multirow[b]{2}{*}{$\begin{array}{c}\text { Vreme } \\
\text { delovanja }\end{array}$} & \multicolumn{3}{|c|}{ Opterećenje } \\
\hline & & $\begin{array}{c}\text { Podešenje } \\
\text { releja }\end{array}$ & $\begin{array}{l}\text { Proračunata } \\
\text { vrednost }\end{array}$ & $\begin{array}{l}\text { Koeficijent } \\
\text { efikasnosti }\end{array}$ & & $\begin{array}{c}\text { Podešenje } \\
\text { releja }\end{array}$ & $\begin{array}{l}\text { Proračunat } \\
\text { a vrednost }\end{array}$ & $\begin{array}{l}\text { Koeficijent } \\
\text { efikasnosti }\end{array}$ \\
\hline \multicolumn{9}{|c|}{ ZAŠTITNA OPREMA - M3 IZVOD } \\
\hline \multicolumn{9}{|c|}{ GRUPA 1 - AKTIVNA } \\
\hline 51 & 0 & - & - & - & - & - & - & - \\
\hline $21 \mathrm{P}$ & 2 & $80.00 \Omega$ & $26.21 \Omega$ & e & - & $80.00 \Omega$ & $353.03 \Omega$ & e \\
\hline $21 \mathrm{P}$ & 3 & $42.20 \Omega$ & $26.21 \Omega$ & 0 & $2.8 \mathrm{~s}$ & $42.20 \Omega$ & $353.03 \Omega$ & e \\
\hline $51 \mathrm{~N}$ & 0 & - & - & - & - & - & - & - \\
\hline $21 \mathrm{G}$ & 2 & $80.00 \Omega$ & $27.20 \Omega$ & e & - & - & - & - \\
\hline $21 \mathrm{G}$ & 3 & $42.23 \Omega$ & $27.29 \Omega$ & 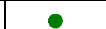 & $2.8 \mathrm{~s}$ & - & - & - \\
\hline \multicolumn{9}{|c|}{ GRUPA 2} \\
\hline \multicolumn{9}{|c|}{ GRUPA 3} \\
\hline \multicolumn{9}{|c|}{ GRUPA 4} \\
\hline
\end{tabular}

Svaki relej može da se klasifikuje na osnovu sledećih kriterijuma:

1) Osetljivost - proverava se da li je razmatrani relej izvan određenih limita (specificiranih unapred zadatih vrednosti), za ranije određenu vrednost tipa i lokacije kvara.

2) Vreme delovanja - proverava se da li je vreme odsecanja kvara u specificiranim limitima. Vreme isključenja kvara mora biti takvo da obezbedi čišćenje kvara u što bržem vremenskom periodu.

3) Opterećenje - proverava se da li je maksimalno opterećenje elementa u specificiranim limitima. Opterećenje štićenog elementa mora biti u okviru zadatih ograničenja kako bi se izbeglo nepotrebno delovanje (okidanje) releja u slučaju velikih opterećenja u mreži.

Iz nepoznatih razloga dolazi do promene uklopnog stanja mreže, tj do zatvaranja NO prekidača prikazanog na slici 5.1. Zadatak ARZ-a je da za novu konfiguraciju mreže predloži koja grupa (tačnije podešenje releja) u okviru zaštitne opreme će biti najadekvatnija.

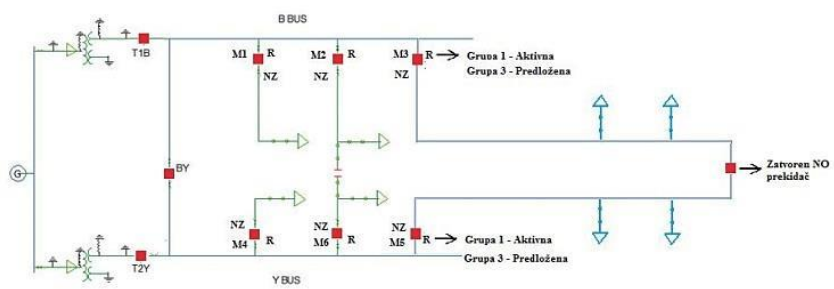

Slika 5.1 - Jednopolna šema distributivne TS nakon promene uklopnog stanja mreže

Nakon uspešnog izvršenja ARZ funkcije, novi izveštaj sa predloženom grupom i informacijama kako bi ta grupa štitila izvod, je dostupan i izgleda kao u tabeli 5.2.

Tabela 5.2. Izveštaj ARZ-a nakon promene uklopnog stanja mreže

\begin{tabular}{|c|c|c|c|c|c|c|c|c|}
\hline \multirow[b]{2}{*}{$\begin{array}{c}\text { Tip } \\
\text { releja }\end{array}$} & \multirow[b]{2}{*}{ Zona } & \multicolumn{3}{|c|}{ Osetljivost } & \multirow[b]{2}{*}{$\begin{array}{c}\text { Vreme } \\
\text { delovanja }\end{array}$} & \multicolumn{3}{|c|}{ Opterećenje } \\
\hline & & $\begin{array}{l}\text { Podešenje } \\
\text { releja }\end{array}$ & $\begin{array}{l}\text { Proračunata } \\
\text { vrednost }\end{array}$ & $\begin{array}{l}\text { Koeficijent } \\
\text { efikasnosti }\end{array}$ & & $\begin{array}{c}\text { Podešenje } \\
\text { releja }\end{array}$ & $\begin{array}{l}\text { Proračunata } \\
\text { vrednost }\end{array}$ & $\begin{array}{l}\text { Koeficijent } \\
\text { efikasnosti }\end{array}$ \\
\hline \multicolumn{9}{|c|}{ ZAŠTITNA OPREMA - M3 IZVOD } \\
\hline \multicolumn{9}{|c|}{ GRUPA 3 - PREDLOŽENA } \\
\hline 51 & 0 & $216.00 \mathrm{~A}$ & $995.02 \mathrm{~A}$ & 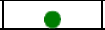 & $1.31 \mathrm{~s}$ & - & - & - \\
\hline $21 \mathrm{P}$ & 2 & $81.57 \Omega$ & $26.21 \Omega$ & 9 & - & - & - & - \\
\hline $21 \mathrm{P}$ & 3 & $108.77 \Omega$ & $26.21 \Omega$ & 9 & $2.80 \mathrm{~s}$ & - & - & \\
\hline $51 \mathrm{~N}$ & 0 & $60.00 \mathrm{~A}$ & $507.87 \mathrm{~A}$ & 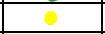 & $2.51 \mathrm{~s}$ & - & - & - \\
\hline $21 \mathrm{G}$ & 2 & $81.77 \Omega$ & $27.22 \Omega$ & e & - & - & - & - \\
\hline $21 \mathrm{G}$ & 3 & $109.00 \Omega$ & $27.31 \Omega$ & 0 & $2.80 \mathrm{~s}$ & - & - & - \\
\hline \begin{tabular}{|l|l|}
$L E$ \\
\end{tabular} & 0 & - & - & - & - & $45.97 \Omega$ & $352.92 \Omega$ & 0 \\
\hline
\end{tabular}

\begin{tabular}{|c|c|c|c|c|c|c|c|c|}
\hline \multicolumn{9}{|c|}{ GRUPA 1 - AKTIVNA } \\
\hline \multicolumn{9}{|c|}{ GRUPA 2} \\
\hline \multicolumn{9}{|c|}{ GRUPA 4} \\
\hline \multicolumn{9}{|c|}{ ZAŠTITNA OPREMA - M5 IZVOD } \\
\hline \multicolumn{9}{|c|}{ GRUPA 3 - PREDLOŽENA } \\
\hline 51 & 0 & $212.00 \mathrm{~A}$ & $681.04 \mathrm{~A}$ & 0 & $1.78 \mathrm{~s}$ & - & - & - \\
\hline $21 \mathrm{P}$ & 2 & $83.48 \Omega$ & $10.63 \Omega$ & e & - & - & - & - \\
\hline $21 \mathrm{P}$ & 3 & $111.30 \Omega$ & $38.20 \Omega$ & 은 & $2.80 \mathrm{~s}$ & - & - & - \\
\hline $51 \mathrm{~N}$ & 0 & $100.00 \mathrm{~A}$ & $368.75 \mathrm{~A}$ & 0 & $1.08 \mathrm{~s}$ & - & - & - \\
\hline $21 \mathrm{G}$ & 2 & $84.05 \Omega$ & $11.59 \Omega$ & 0 & - & - & - & - \\
\hline $21 \mathrm{G}$ & 3 & $112.08 \Omega$ & $41.61 \Omega$ & 9 & $2.80 \mathrm{~s}$ & - & - & - \\
\hline LE & 0 & - & - & - & - & $33.28 \Omega$ & $400.55 \Omega$ & 0 \\
\hline \multicolumn{9}{|c|}{ GRUPA 1 - AKTIVNA } \\
\hline \multicolumn{9}{|c|}{ GRUPA 2} \\
\hline \multicolumn{9}{|c|}{ GRUPA 4} \\
\hline
\end{tabular}

\section{ZAKLJUČAK}

U ovom radu obrađeni su načini realizacije relejne zaštite u severnoameričkim distributivnim mrežama. Detaljno su opisani tipovi releja, kao i njihova funkcionalnost rada. Kroz test primer, posredstvom jednopolne šeme distributivne transformatorske stanice, prikazano je najadekvatnije rešenje koje predlaže ARZ funkcija, pri promeni uklopnog stanja mreže.

U mrežama gde se, u zavisnosti od uklopnog stanja, struje kratkih spojeva, ali i nominalne struje, značajnije menjaju po intezitetu, može doći do neselektivnog delovanja ili do čak vrlo sporog delovanja zaštite. Iz tog razloga je neophodno precizno konfigurisati podešenje relejne zaštite s ciljem da se takvi problemi prevaziđu.

Ovaj rad se u tu svrhu može koristi kao polazna osnova za dalja istraživanja i proračune sa aspekta relejne zaštite, kao i integrisanje u druga softverska rešenja.

\section{LITERATURA}

[1] D. Bekut, Relejna zaštita, Fakultet Tehničkih Nauka Novi Sad, 2009.

[2] V. Strezoski, Elektroenergetski sistemi, Fakultet Tehničkih nauka, Novi Sad 2010.

[3] M. Nimrihter, Distributivni sistemi, Fakultet tehinčkih nauka, Novi Sad, 2001.

[4] T. A. Short, Electric Power Distribution Handbook, Second Edition, 2014.

\section{Kratka biografija:}

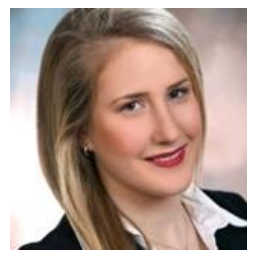

Dragana Vidrić je rođena u Zrenjaninu 1995. godine. Osnovne studije je završila na Fakultetu tehničkih nauka 2018. godine na departmanu Elektrotehnika i računarstvo - Elektroenergetski sistemi. Master rad je odbranila 2019. godine, na istom fakultetu na smeru Energetika, elektronika i telekomunikacije Elektroenergetski sistemi. 